\title{
Nodal generalised osteoarthritis is an autoimmune disease
}

\author{
Michael Doherty, Martin Pattrick, Richard Powell
}

Rheumatology Unit, Nottingham NG5 1PB $M$ Doherty M Pattrick

Department of

Immunology,

Queen's Medical Centre, Nottingham $\mathbf{R}$ Powell

Correspondence to: Dr Doherty.

Accepted for publication 16 March 1990 City Hospital,

\begin{abstract}
Nature of osteoarthritis
Osteoarthritis (OA), the commonest abnormality to affect synovial joints, has accompanied man throughout his evolutionary history, and a similar process occurs in other animals that fuse epiphyses in the adult. ${ }^{1-3}$ Such prevalence and phylogenetic preservation suggest that $O A$ is a process rather than a disease, reflecting the response of articular tissues to extrinsic or intrinsic insult, or both. ${ }^{45}$ The recognised synthetic activity of osteoarthritic tissues, ${ }^{4-6}$ the radiographic remodelling and favourable outcome seen in many patients with $O A,,^{7-9}$ and the prevalence of asymptomatic 'disease' 1011 support the concept of $\mathrm{OA}$ as a repair process. ${ }^{45}$ Like any repair process, OA may succeed or fail when responding to a variety of triggering or perpetuating insults (fig 1). The pathogenesis and variability of $O A$ are poorly understood, but multiple factors, including genetic, constitutional, and environmental, are likely to play a part. ${ }^{312} 13$ Marked variability in the nature and chronicity of the insult(s), and host differences in effective repair response, result in the confusing heterogeneity of radiographic and clinical manifestations.
\end{abstract}

The 'subset' of nodal generalised OA (NGOA) In an attempt to understand OA better and to identify factors initiating and influencing compensation (no symptoms, good outcome) or decompensation (symptoms, functional impair-

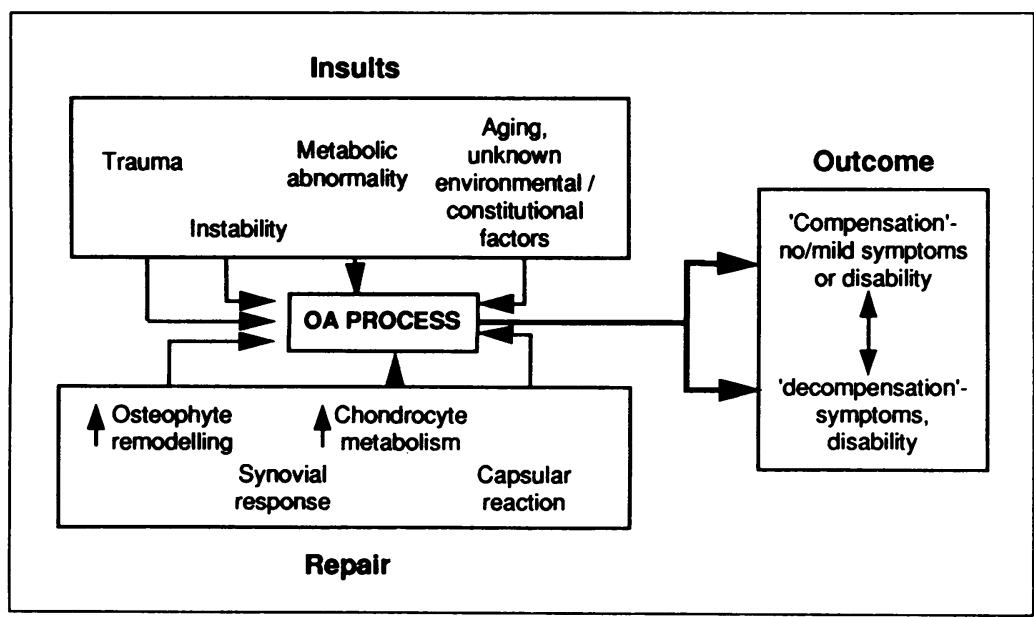

Figure 1 Representation of osteoarthritis as a repair process that may compensate or fail in response to a variety of insults. ment, 'joint failure'), OA has been increasingly divided into clinically determined subsets. ${ }^{3}$ Such categorisation has been by distribution of joint disease (generalised, pauciarticular, mono$\operatorname{articular}^{14}$; predominance of certain radiographic features ('atrophic', 'hypertrophic'15); associated crystal deposition (pyrophosphate arthropathy, ${ }^{16}$ apatite associated destructive arthritis ${ }^{17}$ ); and presumed aetiological factorsfor example, epiphysial dysplasia, Kashin-Beck disease. Such subsetting, especially for common forms of OA, has proved problematic because of overlap, ${ }^{16} 18$ temporal transition from one subset to another, ${ }^{16} 19$ and difficulties in radiographic interpretation and crystal identification. ${ }^{19-21}$ Nevertheless, several groups are generally accepted. ${ }^{3}$

Nodal generalised OA, the best recognised subset, is characterised by polyarticular hand OA (principally interphalangeal and first carpometacarpal joints), female preponderance, early symptomatic inflammatory component, and Heberden (with or without Bouchard) node formation, or both ${ }^{31422}$ : of all OA subsets, familial tendency is particularly recognised. ${ }^{13}$ Erosive OA is a less common generalised subset sharing many features of NGOA but differing in having marked subchondral erosive change, a more florid and prolonged inflammatory component, and a tendency to intra-articular osseous fusion. ${ }^{32324}$ Minor subchondral erosions in NGOA, however, are not uncommon and whether erosive $\mathrm{OA}$ is a discrete subset or merely the more severe end of the NGOA spectrum has been questioned. ${ }^{25}$ Many elderly subjects have patchy hand interphalangeal OA or nodes: this may relate to obvious prior trauma, but is often asymptomatic and apparently sporadic. Although there is no sharp division between such hand OA and NGOA, the latter is classically symptomatic in middle age, presenting as a stuttering-onset 'monoarthritis multiplex', is unrelated to obvious trauma, and affects most if not all rays. At sites other than the hand, such as the hip, the tendency to bilateral disease and to diffuse (concentric/central) rather than focal (superolateral) cartilage loss 26 further supports the separation of NGOA as an inflammatory subset of OA.

Genetic associations

Surprisingly, despite marked familial predis- 
position, few studies have searched for genetic markers in NGOA. ${ }^{13}$ Until recently only four studies had examined the frequencies of HLA antigens, with conflicting results: Lawrence et al reporting increased frequency of HLAAlB8, ${ }^{28}$ Brodsky et al an increase in HLA-B8, ${ }^{29}$ and two studies finding no associations. ${ }^{30} 31 \mathrm{~A}$ recent large study by Pattrick et al, however, confirmed increased frequency of HLA-A1B8 in 90 unrelated patients with NGOA (relative risk compared with reference population $2 \cdot 79$; $\mathrm{p}<0.01$ ); an independently increased frequency of the $M Z \alpha_{1}$ antitrypsin phenotype was also shown (relative risk $3.7 ; \mathrm{p}<0.01$ ). ${ }^{32}$ Although in theory relative $\alpha_{1}$ antitrypsin deficiency might enhance enzyme related joint tissue damage and thus promote development of OA, occurrence of normal $\alpha_{1}$ antitrypsin concentrations in all patients favoured genetic linkage rather than protease inhibitor deficiency. Both the HLA and $\alpha_{1}$ antitrypsin associations related to development rather than severity as judged by radiographic hand OA scores. Interestingly, a subgroup with erosive OA had both higher radiographic scores (corrected for the presence of erosions) and increased frequency of the MS $\alpha_{1}$ antitrypsin phenotype $(\mathrm{p}<0.001)$, perhaps supporting the concept of erosive $\mathrm{OA}$ as severe NGOA with additional genetic factors influencing severity.

These findings are of particular interest as HLA-A1B8 is in linkage disequilibrium with DR3 and commonly associates with conditions in which an autoimmune component is well recognised-for example, systemic lupus erythematosus, ${ }^{33}$ autoimmune thyroid disease, ${ }^{34}$ Sjögren's syndrome. ${ }^{33}$ An association with a particular $\alpha_{1}$ antitrypsin phenotype may also be relevant to an autoimmune pathogenesis because $\alpha_{1}$ antitrypsin is encoded on chromosome 14 near the $\mathrm{Gm}$ locus for IgG, ${ }^{35}$ and it is conceivable that genetically determined variability in immunoglobulin heavy chain morphology could predispose to autoimmune phenomena and resultant disease. ${ }^{36-38}$ Investigation of $\mathrm{Gm}$ allotypes, or other more directly involved gene products in linkage with $\alpha_{1}$ antitrypsin on chromosome 14, might therefore be of relevance in NGOA.

Other studies have concentrated on genes relating to collagen formation on the assumption that inherent defects of particular forms of type II collagen may predispose to biomechanical faults in cartilage and 'decompensation' under normal mechanical loading. Palotie et al recently described two Finnish families with premature 'generalised $\mathrm{OA}^{\prime} \cdot{ }^{39}$ Using restriction fragment length polymorphisms within and around the type II collagen gene on chromosome 12 , they noted linkage between the cartilage specific gene (COL2Al) and the development of arthritis, supporting the primacy of cartilage structure (specifically the collagen network) in development of 'joint failure'. Although clinical details were sparse, the age of onset, distribution, and autosomal dominant inheritance favoured dysplasia rather than NGOA. Hull and Pope reported increased frequency of a closely situated restriction fragment length polymorphism $(B a m H I)$ in a group
Observations which support autoimmune mechanisms in nodal generalised osteoarthritis

Genetic associations:
HLA-A1B8
$M Z$ a antitrypsin
Female preponderance
Perimenopausal onset
(Hormonal influence on disease expression)
Association with other autoimmune disease
Sjögren's syndrome (?erosive osteoarthritis only)
Thyroid disease
Immunological findings in synovium and cartilage
Increased frequency of rheumatoid factor

of women with OA affecting more than one joint before age $60,{ }^{40}$ though a study of COL2 genes in a large number of English patients with well defined NGOA failed to show any associations (Priestley L, Fergusson C, Ogilvie D, et al, unpublished data), thus questioning the relevance of collagen genes to the NGOA subset. In summary therefore, the genetic information available for NGOA concurs only to suggest that immune mechanisms might be involved in its pathogenesis.

\section{Hormonal influence on disease expression} What further support is there for the possibility that NGOA is an autoimmune disease? In addition to shared genetic (HLA) associations, two common characteristics of autoimmune disease are female preponderance and hormonal influence on disease expression (table). Symptomatic NGOA is principally a female condition with onset commonly around the menopause: indeed this association is so striking it was previously labelled 'menopausal arthritis'. ${ }^{41}$ No such association with non-nodal OA has been made, again supporting separation of NGOA as a distinct subset.

The influence of sex hormones on development of $O A$, including a suggested relation with previous hysterectomy, ${ }^{42}$ has recently been reviewed. ${ }^{43}$ The positive associations with obesity, perimenopausal onset (changing sex hormone profiles), fibroids, and dysfunctional uterine bleeding, and the negative correlation with osteoporosis may all be explained by an absolute or relative oestrogen excess. ${ }^{43}$ Support for this comes from certain animal models of OA which show deterioration with oestrogens and improvement with tamoxifen. ${ }^{44}$ Suggested mechanisms usually emphasise the direct hormonal effects on cartilage matrix homeostasis $^{43} 44$ : this is not altogether surprising as cartilage, rightly or wrongly, remains the main focus for research interest in OA. ${ }^{45}$ An equally valid interpretation, however, is that hormonal fluctuation/imbalance may predispose to NGOA through modulation of the immune system rather than by connective tissue activity, there being abundant evidence for hypoandrogenic/hyperoestrogenic states being contributory to development or exacerbation of 'autoimmune disease' through such effects. ${ }^{46}$

\section{Autoimmune disease associations}

An association with other autoimmune phenomena would obviously strengthen the case. Although the question of autoimmunity in 
NGOA has not been specifically considered, several observations offer tantalising clues. An increased prevalence of autoimmune thyroid disease was reported in a controlled study of patients with pyrophosphate arthropathy, most of whom were women, many with $\mathrm{NGOA}^{9}{ }^{47}$ : the lack of an association between hypothyroidism and chondrocalcinosis ${ }^{48}$ suggests that this might have arisen through association with NGOA. The reported association between Sjögren's syndrome and erosive $\mathrm{OA}^{49}$ is also of interest, particularly if erosive $\mathrm{OA}$ is a severe rather than separate form of generalised OA. ${ }^{5}$ Similarly, the increased frequency of rheumatoid factors in $\mathrm{NGOA}^{14} 50$ may reflect an autoimmune diathesis. Controlled studies determining frequencies of organ specific antibodies, rheumatoid factors, and autoimmune disease in NGOA would thus seem warranted.

\section{Immunohistochemical evidence}

The increasingly recognised inflammatory component in $\mathrm{OA}, 5152$ and immunohistological

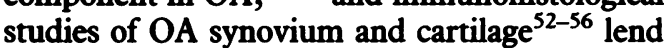
further support to the involvement of immune mechanisms in pathogenesis. It is possible of course that the finding of immunoglobulin (particularly IgA), complement, and immune complexes' in OA cartilage, ${ }^{22} 5256$ and the identification of lymphoid and mononuclear populations in OA synovium (identical with, though less widespread than those found in rheumatoid arthritis ${ }^{525355}$, reflect merely non-specific reaction to tissue damage rather than inflammation driven primarily by immunological events. Nevertheless, it is of interest that such cartilage and synovial abnormalities (at the hip) are more common and pronounced in 'primary' polyarticular NGOA than in 'secondary' pauciarticular $\mathrm{OA},{ }^{22} 52$ again supporting the possibility of a systemic (? primary) rather than just local (secondary) inflammatory reaction.

Although cartilage might enjoy the status of immunological privilege by virtue of its anatomic structure, autoimmunity to cartilage might theoretically develop if sequestered antigens were exposed or became autoantigenic by interaction with exogenous or intrinsic factors. Anticollagen antibodies and cell mediated immune responses to collagen have indeed been shown in patients with OA, but also in patients with acute joint trauma and inflammatory joint disease. ${ }^{57}$ Whether or not such immune responses play a part in perpetuation of joint disease, their lack of specificity favours a secondary rather than primary role in causation. If autoimmunity plays a part in NGOA it is most likely to exert its initial inflammatory effects on non-cartilaginous articular tissues. From a clinical standpoint the synovium/capsule (or even bone) would seem a likely target.

\section{Single shot insult}

As in all arthropathies the distribution of joint disease in NGOA remains unexplained. Hypotheses to explain preferential distribution include differing mechanical forces at different sites ${ }^{59} \mathbf{6 0}$

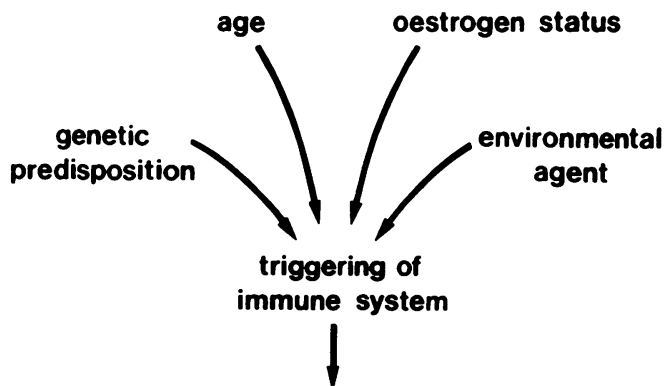

symptomatic

monoarthritis multiplex

repair process

compensated joint damage in pattern of 'NGOA'

Figure 2 Outline of nodal generalised osteoarthritis (NGOA) as an autoimmune disease.

and effects on joint design resulting from varying rates of evolutionary change. ${ }^{61}$ The bilateral, 'symmetrical' distribution of NGOA is also unexplained. Although the role of neurogenic factors in the symmetry of inflammatory joint diseases has been discussed, ${ }^{62}$ an alternative hypothesis for autoimmune based disease relates to the selectivity of pathways undertaken by circulating lymphocytes, which limits the distribution of immune mediated disease. ${ }^{63}$ The symmetry and distribution of disease might thus primarily reflect predetermined 'homing' of lymphocytes rather than targeting determined by local events-for example, mechanical insult and usage. 59

A generally good prognosis has recently been confirmed by a controlled study of patients with established NGOA which showed that compensated OA has little symptomatic or functional impact on the aging hand. ${ }^{64}$ If symptomatic NGOA is an autoimmune condition it would thus seem to be a selective 'single shot' disease affecting target joints of genetically predisposed subjects at a time conditioned by age, hormonal and other constitutional factors. There is increasing evidence that many autoimmune diseases are triggered by external (predominantly infective) agents, ${ }^{65} 66$ and an unidentified external trigger for NGOA may exist. Whatever its nature, this immune mediated joint insult triggers a hypertrophic repair process which, despite marked cartilage loss, then usually compensates in terms of symptoms and function. Once the inflammatory phase has settled the patient is left with architecturally abnormal joints, which we recognise as 'OA' (fig 2).

Inclusion of NGOA within the autoimmune umbrella may further stimulate interest in what has previously been regarded by some as an unexciting 'degenerative' condition. From currently available information it would seem that further studies of genetic, constitutional, and immunological factors are warranted if we are to improve our understanding of NGOA, and hence the inherent repair process of synovial joints.

We are indebted to the Arthritis and Rheumatism Council for financial support. 
1 Sokoloff $\mathrm{L}$. Natural history of degenerative joint disease in small laboratory animals. Pathologic anatomy of degenerative joint disease in mice. AMA Archives of Pathology 1956, 62: 118-28.

2 Bollet A J. An essay on the biology of ostecarthritis. Arthritis Rhewn 1969; 12: 152-63.

3 Peyron J G. Epidemiologic and etiologic approach of osteoarthritis. Semin Arthritis Rhewon 1979; 8: 288-306.

4 Sokoloff L. Osteoarthritis as a remodelling process. f Rheumatol 1987; 14: 7-10.

5 Radin E L, Burr D B. Hypothesis: joints can heal. Semin Arthritis Rhewm 1984; 13: 293-302.

6 Rothwell A G, Bentley G. Chondrocyte multiplication in osteoarthritic articular cartilage. $\mathcal{f}$ Bome foint Surg [Br]

7 Hernborg J S, Nilsson B E. The natural course of untreated osteoarthritis of the knee. Clin Orthop 1977; 123: 131-7.

8 Danielsson L G. Incidence and prognosis of coxarthrosis. Acta Orthop Scand 1964: suppl 64.

9 Doherty M. Pyrophosphate arthropathy-a clinical study. Cambridge: Cambridge University, 1987. (MD thesis.)

10 Cobb S, Merchant $W$ R, Rubin T. The relation of symptoms to osteoarthritis. F Chronic Dis 1957; 5: 197-204.

11 Lawrence J S, Bremner J M, Beir F. Osteoarthritic prevalence in the population and relationship between symptoms and $\mathrm{x}$-ray changes. Ann Rhewem Dis 1966; 25: 1-24.

12 Hadler N M, Gillings D B, Imbus H R, et al. Hand structure and function in an industrial setting. Influence of three patterns of stereotyped, repetitive usage. Arthritis Rheum 1977; 20: 1019-25.

13 Harper P, Nuki G. Genetic factors in osteoarthritis. In: Nuki G, ed. The aetiopathogemesis of osteoarthrosis. London: Pitman Medical, 1980; 184-201.

14 Kellgren J H, Moore R. Generalised osteoarthritis and Heberden's nodes. $\mathrm{Br}$ Med $\mathcal{F}$ 1952; i: 181-7.

15 Solomon L. Patterns of osteoarthritis of the hip. 7 Bone foint Surg [Br] 1976; 58: 176-83.

16 Doherty M, Dieppe P A. Clinical aspects of calcium pyrophosphate dihydrate crystal deposition. Rhewomatic Diseases Clinics of North America 1988; 14: 395-414.

17 Dieppe P A, Doherty M, MacFarlane D G, Hutton C W Bradfield J W, Watt I. Apatite-associated destructive arthritis. Br $\mathcal{Y}$ Rhewmatol 1984; 23: 84-91.

18 Doherty M, Watt I, Dieppe P A. Influence of primary generalised osteoarthritis on development of secondary ostecarthritis. Lancet 1983; ii: 8-11.

19 Dieppe P, Watt I. Crystal deposition in osteoarthritis: an opportunistic event? Clin Rheum Dis 1985; 2: 367-92.

20 Schumacher H R Jr, Sieck M S, Rothfuss S, et al. Reproducibility of synovial fluid analysis. A study among four laboratories. Anthritis Rhewom 1986; 29: 770-4.

21 Hasselbacher P. Variation in synovial fluid analysis by hospital laboratories. Arthritis Rhewn 1987; 30: 637-42.

22 Cooke T D V. Pathogenetic mechanisms in polyarticular osteoarthritis. Clin Rhewm Dis 1985; 2: 203-38.

23 Crain D C. Interphalangeal osteoarthritis. JAMA 1961; 175: $1049-53$.

24 Peter J B, Pearson C M, Marmor L. Erosive osteoarthritis of the hands. Arthritis Rhewm 1966; 9: 365-88.

25 Cushnaghan J, Cobby M, Creamor P, Watt I, Dieppe P A. Erosive osteoarthritis: a longitudinal, comparative study of 24 cases. Br J Rhewmatol 1989; 28 (suppl 2): 102.

26 Marks J S, Stewart I M, Hardinge K. Primary osteoarthritis of the hip and Heberden's nodes. Ann Rheum Dis 1979; 38 : 107-11.

27 McGoldrick F, O'Brien T. Osteoarthritis of the hip and Heberden's nodes. Amn Rhewen Dis 1989; 48: 53-5.

28 Lawrence J S, Gelsthorpe K, Morell G. Heberden's nodes and $H \mathrm{I}$ markers in generalised ostecarthritis. $\mathcal{J} R$ hetumatol 1983; 10 (suppl 9): 32-3.

29 Brodsky A, Appelboan T, Govaerts A, Famey J P. Antigens HLA et nodosites d'Heberden. Acta Rhumatologica 1979 , 3: 95-103.

30 Ercilla M G, Brancos M A, Breysse Y, et al. HLA antigens in Forestier's disease, ankylosing spondylitis, and polyarthrosis of the hands. If Rherumatol 1977; 4 (suppl 3) $89-93$.

31 Benavides G, Cervantes A, Silva B, Katona G, Lardizabal J. HLA and Heberden's nodes in Mexican mestizos. Clin Rhewematol 1985; 4: 97-8.

32 Pattrick M, Manhire A, Milford Ward A, Doherty M. HLA A, B antigens and alpha-1-antitrypsin phenotypes in noda generalised osteoarthritis and erosive osteoarthritis. Ann

Rhewe Dis 1989; 48: 470-5.
33 Goldstein R, Arnett F C. The genetics of rheumatoid disease in man. Rherematic Diseases Clinics of North America 1987; 13: 463-510.

34 Dahlberg P A, Holmlund G, Karlsson F A, Safwenberg J; HLA-A, -B, -C, and -DR antigens in patients with Graves disease and correlations with signs and
$35 \operatorname{Cox}$ D W, Markovic V D, Teshima I E. Genes for immunoglobulin heavy chains and alpha-1-antitrypsin are localised to specific regions of chromosome 14q. Nature 1982; 297: 428-30.

36 Nakao Y, Matsumoto H, Miyazaki T, et al. IgG heavy chain allotypes $(\mathrm{Gm})$ in autoimmune diseases. Clin Exp Immunol 1980; 42: 20-6.

37 Whittingham S, Mathews J D, Schanfield M S, et al. Interactive effect of $\mathrm{Gm}$ allotypes and HLA-B locus antigens on the human antibody response to a bacterial antigens on the human antibody response

38 Baldwin R N, Mijovic C, Fletcher J, Bradwell A R, Barnett A H, Hockaday T D R. Immunoglobulin heavy chain phenotypes and background retinopathy in non-insulin dependent diabetics. Br Med f 1988; 297: 1104-5.

39 Palotie A, Vaisanen P, Ott J, et al. Predisposition to familial osteoarthritis linked to type II collagen gene. Lancet 1989; i: 924-7.

40 Hull R, Pope F M. Osteoarthritis and cartilage collagen genes. Lancet 1989; i: 1337-8.

41 Cecil $R$ L, Archer B H. Classification and treatment of chronic arthritis. FAMA 1926; 87: 741-6.

42 Spector T D, Brown G C, Silman A J. Increased rates of previous hysterectomy and gynaecological operations in
women with osteoarthritis. Br Med f 1988; 297: 899-900.

43 Spector T D, Campion G D. Generalised osteoarthritis: a hormonally mediated disease. Ann Rheum Dis 1989; 48: 523-7.

44 Rosner I A, Goldbery V M, Moskowitz R W. Estrogens and osteoarthritis. Clin Orthop 1986; 213: 77-83.

45 Doherty M. Chondroprotection by NSAIDs. Ann Rheum Dis 1989; 48: 619-21.

46 Ansar Ahmed S, Talal N. Sex hormones and autoimmune rheumatic disorders. Scand $\mathcal{Y}$ Rheumatol 1989; 18: 69-76.

47 Alexander G M, Dieppe P A, Doherty M, Scott D G. Pyrophosphate arthropathy: a study of metabolic associations and laboratory data. Ann Rheum Dis 1982; 41: 377-81.

48 Komatireddy G R, Ellman M H. Brown N L. Lack of association between hypothyroidism and chondrocalcinosis. association between hypothyroidis

49 Shuckett R, Russell M L, Gladman D D. Atypical erosive osteoarthritis and Sjögren's syndrome. Ann Rherm Dis 1986; 45: 281-8.

50 Acheson R M, Collart A B. New Haven survey of join diseases. XVII. Relationship between some systemic characteristics and osteoarthrosis in a general population. Ann Rheum Dis 1975; 34: 379-87.

51 Altman R D, Gray R. Inflammation in osteoarthritis. Clin Rheum Dis 1985; 11: 353-65.

52 Cooke T D V. Immune pathology in polyarticular osteoarthritis. Clin Orthop 1986; 213: 41-9.

53 Lindblad S, Hedfors E. Arthroscopic and immunohistologic characterization of knee joint synovitis in osteoarthritis. Arthritis Rhewm 1987; 30: 1081-8.

54 Revell P A, Mayston V, Lalor P, Mapp P. The synovial membrane in osteoarthritis: a histological study including membrane in osteoarthritis: a histological study including the characterisation of the cellular infltrate present in Ann Rhewm Dis 1988; 47: 300-7.

55 Johnell $O$, Hulth A, Henricson A. T-Lymphocyte subsets and HLA-DR-expressing cells in the osteoarthritic synovialis. Scand $\mathcal{F}$ Rhewmatol 1985; 14: 259-64.

56 Goldberg V M, Kresina T F. Immunology of articular cartilage. $\mathcal{F}$ Rheumatol 1987; 14: 73-6.

57 Jasin H E. Autoantibody specificities of immune complexe sequestered in articular cartilage of patients with rheumatoid arthritis and osteoarthritis. Arthritis Rheum 1985; 28 . 241-8.

58 Morgan K. What do anti-collagen antibodies mean? Ann Rhewom Dis 1990; 49: 62-5.

59 Radin E L, Parker H G , Paul I L. Pattern of degenerative arthritis. Preferential involvement of distal finger-joints. Lancet 1971; i: 377-9.

60 Radin E L. Aetiology of osteoarthritis. Clin Rheum Dis 1976; 2: 509-22.

61 Hutton $C$ W. Generalised osteoarthrosis: an evolutionary problem? Lancet 1987; i: 1463-5.

62 Levine J D, Goetzl E J, Basbaum A Z. Contribution of the nervous system to the pathophysiology of rheumatoid arthritis and other polyarthritides. Rheumatic Diseases Clinics of North America 1987; 13: 369-83.

63 Goudie R B, Soukop M, Dagg J H, Lee F D. Hypothesis symmetrical cutaneous lymphoma. Lancet 1990; 335: 316-8.

64 Pattrick M, Aldridge S, Hamilton E, Manhire A, Doherty M. A controlled study of hand function in nodal and erosive osteconrthritis. Anin Rhewen Dis 1989; 48: 978-82.

65 Anonymous. The viral setiology of rheumatoid arthritis [Editorial]. Lancet 1984; i: 772-4.

66 Oldstone M. Molecular mimicry and autoimmune disease. Cell 1987; 50: 819-20. 